\title{
Awareness and Attitudes Regarding Breast Cancer and Breast Self- Examination among Females in Umm Al-Qura University, Mekkah, Saudi Arabia
}

\author{
Rawaa K. Damanhouri \\ Umm AI-Qura University Medical Center, Mekkaha, Saudi Arabia
}

\begin{abstract}
Background: Among Saudi patients, the number of women with breast cancer was increased steadily from 1990 to 2010 . Huge efforts in increasing the level of breast cancer awareness are attempting in the Kingdom.

Objectives: To assess the level of knowledge about breast cancer, attitude and practicing breast self-examination (BSE) among females in Umm Al-Qura University. Makkah, Saudi Arabia.

Subjects and methods: A cross sectional study was carried out that included student, employees, and academics staff in Umm Al-Qura university, Makkak, Saudi Arabia. A selfadministered Arabic valid questionnaire was used for data collection. It has 3 main parts: (i) 2 questions to determine the demographic background of respondents, (ii) 9 questions to assess the respondent's awareness about breast cancer, and (iii) 2 questions about their attitude towards breast cancer awareness method (BSE).

Results: The study included 95 participants. Majority of them $(70.6 \%)$ aged below 25 years. Only $14.7 \%$ had a family history of breast cancer. Almost all of the respondents have heard about breast cancer (98.9\%) and breast self-examination (91.6\%). The commonest sources of information about breast cancer and breast self-examination were social media (49.5\%) and place of study/work (47.3\%). Breast self-examination was
\end{abstract}

\section{INTRODUCTION}

Breast cancer is the commonest cause of cancer death in women worldwide. ${ }^{1}$ The American Cancer Society estimated the numbers of new cancer cases and deaths that will occur each year in the United States. In the current year (2016), it is estimated that $1,685,210$ new cancer cases and 595,690 cancer deaths will occur. ${ }^{2}$ Among Saudi patients, the number of women with breast cancer was increased steadily from 1990 to 2010 , on the basis of the number of cases; the percentage distribution of breast cancer appears to be increasing as there were 1152 cases in 2008 in comparison with 1308 in 2009, and 1473 in 2010. ${ }^{3}$ Breast cancer ranked first and accounts of $27.4 \%$ among all newly diagnosed female cancers (5378) in the year 2010. ${ }^{3}$

Moreover, around $73 \%$ of breast cancer cases in the Kingdom of Saudi Arabia decided to consult the doctor at a very advanced stage of disease that cannot be cured compared with $30 \%$ of performed by only $32.6 \%$ of women. Overall, adequate knowledge regarding breast cancer and breast selfexamination was observed among $82.1 \%$ of the respondents.

Conclusion: Despite the knowledge of women regarding breast cancer and BSE was adequate in general; the practice of screening BSE was suboptimal. Therefore, there is a need to teach women about the importance of practices for early detection techniques.

Keywords: Breast Cancer, Breast self-examination, Awareness, Saudi Arabia.

${ }^{*}$ Correspondence to:

Dr. Rawaa K. Damanhouri, Umm Al-Qura University Medical Center, Mekkaha, Saudi Arabia.

Article History:

Received: 26-10-2016, Revised: 06-11-2016, Accepted: 23-11-2016

\begin{tabular}{|l|c|}
\hline \multicolumn{2}{|c|}{ Access this article online } \\
\hline $\begin{array}{l}\text { Website: } \\
\text { www.ijmrp.com }\end{array}$ & Quick Response code \\
\hline DOI: & \\
10.21276/ijmrp.2016.2.6.039 & \\
\hline
\end{tabular}

cases in developed countries. ${ }^{4}$ According to WHO, early detection methods are remain the corn stones in improving breast cancer outcome and survival. ${ }^{5}$ This can be achieved by increasing awareness of early disease signs and symptoms in populations, in conjugation with Mammography screening programmers. ${ }^{5}$ Even there is no evidence on the effect of screening through breast selfexamination (BSE). However, the practice of BSE has been seen to empower women, taking responsibility for their own health. Therefore, breast self-examination is recommended for raising awareness among women at risk rather than as a screening method. ${ }^{5}$

The present study aimed to assess the level of knowledge about breast cancer, attitude and practicing breast self-examination (BSE) among females in Umm Al-Qura University. Makkah, Saudi Arabia. 


\section{MATERIALS AND METHODS}

Using a cross sectional research design, this study examined the knowledge of female in Umm Al-Qura University, Makkah, Saudi Arabia as regards breast cancer, in addition to their practice of BSE.

The target population of the study included female students, employees, and academics staff in university without exclusion. The average age of those population ranged between 18-60 years. A quantitative research approach was conducted using selfadministered survey. The used questionnaire was adapted from previous study which has been conducted in University the University of Lagos, Nigeria. ${ }^{6}$ After attaining permission to use this questionnaire, it was translated into Arabic language, and modified to be appropriate for cultural differences. Validity of the Arabic version was ascertained by three family medicine consultants.

The questionnaire has 3 main parts distributed on 13 questions, with following subclasses: (i) 2 questions to determine the demographic background of respondents, (ii) 9 questions to assess the respondent's awareness about breast cancer, and (iii) 2 questions about their attitude towards breast cancer awareness method (BSE).

The questionnaire was hand-delivered by researcher throughout 4 days starting in 23 October 2016, with explanation of the main objective of the study and assurance of confidentiality and anonymity of data. Respondents were informed that participation in this study was voluntary.

Among 104 completed questionnaires, 9 of them were voided due to incompleteness or multiple choices while 95 of which had required criteria were analyzed.

Analysis of date was done using SPSS software, version 22. Frequency and percentages were utilized for data description whereas chi-square and Fischer exact tests were used for data analysis and $p$-value less than 0.05 was utilized as a cut of level for statistical significance.
Table 1: Demographic Profile of Respondents

\begin{tabular}{lcc}
\hline Variable & Number & (\%) \\
\hline Age & & \\
$<25$ year & 66 & 70.6 \\
25-35 year & 14 & 4.7 \\
$>35$ year & 14 & 14.7 \\
Family history of breast cancer & & \\
Yes & 14 & 14.7 \\
No & 81 & 85.3 \\
\hline
\end{tabular}

RESULTS

Of 104 questionnaires distributed, 95 were returned, yielding a response rate of $91.3 \%$. Table 1 shows that majority of respondent $(70.6 \%)$ aged below 25 years and only $14.7 \%$ had a family history of breast cancer.

Table 2 shows the level of breast cancer and breast selfexamination awareness among the respondents. Almost all of the respondents have heard about breast cancer $(98.9 \%)$ and breast self-examination $(91.6 \%)$. Most of them $(75.8 \%)$ knew that breast cancer is common in kingdom of Saudi Arabia. All of them thought that it can be detected early and $98.9 \%$ knew that early detection can modify the disease results. Most of the of the respondents $(73.7 \%)$ knew that breast self-examination should be started at age of 20 years, $67.3 \%$ knew that breast self-examination should repeated monthly and almost half of them (49.5\%) recognized that breast self-examination should be performed after menstrual period.

The commonest sources of information about breast cancer and breast self-examination were social media $(49.5 \%)$ and place of study/work (47.3\%) as illustrated in figure 1.

Table 3 demonstrates that the breast self-examination was performed by only $32.6 \%$ of women. Of those who never performed breast self-examination, the main reasons were decrease the confident of ability in perform it in right way (34.4\%), haven't any symptoms of breast cancer $(25 \%)$ and ignorance of its performance $(17.2 \%)$.

Table 2: Respondents knowledge of breast cancer and breast self-examination

\begin{tabular}{|c|c|c|c|}
\hline Question & & Number & $(\%)$ \\
\hline \multirow[t]{2}{*}{ Have you heard before about breast cancer? } & Yes & 94 & 98.9 \\
\hline & No & 1 & 1.1 \\
\hline \multirow[t]{2}{*}{ Is it common in kingdom of Saudi Arabia? } & Yes & 72 & 75.8 \\
\hline & No & 23 & 24.2 \\
\hline \multirow[t]{2}{*}{ Do you think it can be detected early? } & Yes & 95 & 100 \\
\hline & No & 0 & 0.0 \\
\hline \multirow[t]{2}{*}{ Can early detection modify the disease result? } & Yes & 94 & 98.9 \\
\hline & No & 1 & 1.1 \\
\hline \multirow{2}{*}{ Have you heard before about breast self-examination? } & Yes & 87 & 91.6 \\
\hline & No & 8 & 8.4 \\
\hline \multirow[t]{3}{*}{ At what age breast self-examination should begin? } & 20 years & 70 & 73.7 \\
\hline & 30 years & 18 & 18.9 \\
\hline & 40 years & 7 & 7.4 \\
\hline \multirow[t]{4}{*}{ How often breast self-examination should repeated? } & Daily & 1 & 1.1 \\
\hline & Weekly & 3 & 3.2 \\
\hline & Monthly & 64 & 67.3 \\
\hline & Yearly & 27 & 28.4 \\
\hline \multirow[t]{4}{*}{ What is the proper time to perform breast self-examination? } & Before menstrual period & 9 & 9.5 \\
\hline & During menstrual period & 11 & 11.5 \\
\hline & After menstrual period & 47 & 49.5 \\
\hline & Any time & 28 & 29.5 \\
\hline
\end{tabular}




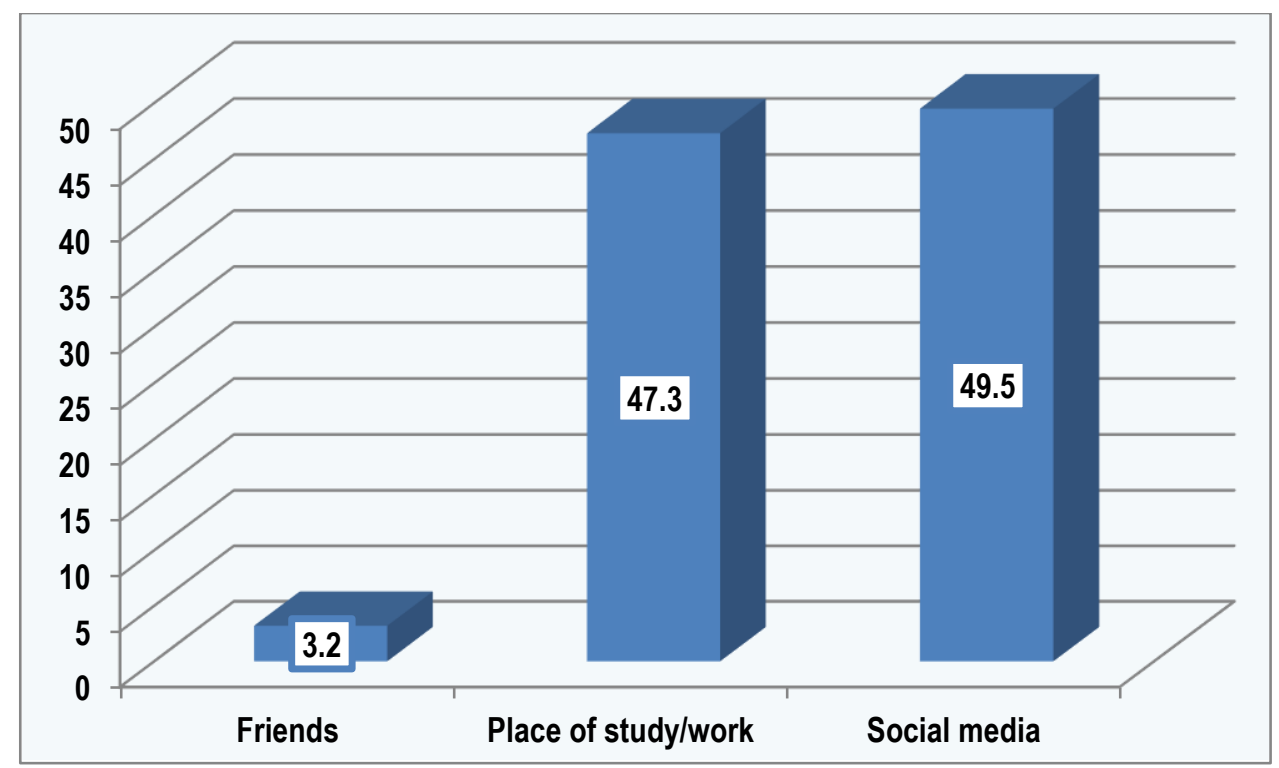

Figure 1: Source of information about breast cancer and breast self-examination.

Table 3: Attitude of the respondents to breast self-examination

\begin{tabular}{lcc}
\hline Question & Number & (\%) \\
\hline Have you done breast self-examination before? & 31 & 32.6 \\
Yes & 64 & 64.4 \\
No & & \\
If the answer was no, why? & 11 & 17.2 \\
I don't know how to do it & 22 & 34.4 \\
I am not sure I can do it in the right way & 2 & 3.1 \\
I don't believe in the accuracy of that test in diagnosis of breast cancer & 3 & 4.7 \\
I feel shame of do it & 16 & 25.0 \\
I don't have any symptoms of breast cancer & 3 & 4.7 \\
I think I can never have breast cancer. & 7 & 10.9 \\
I am scared of finding any sign of breast examination during examination & 7 \\
\hline
\end{tabular}

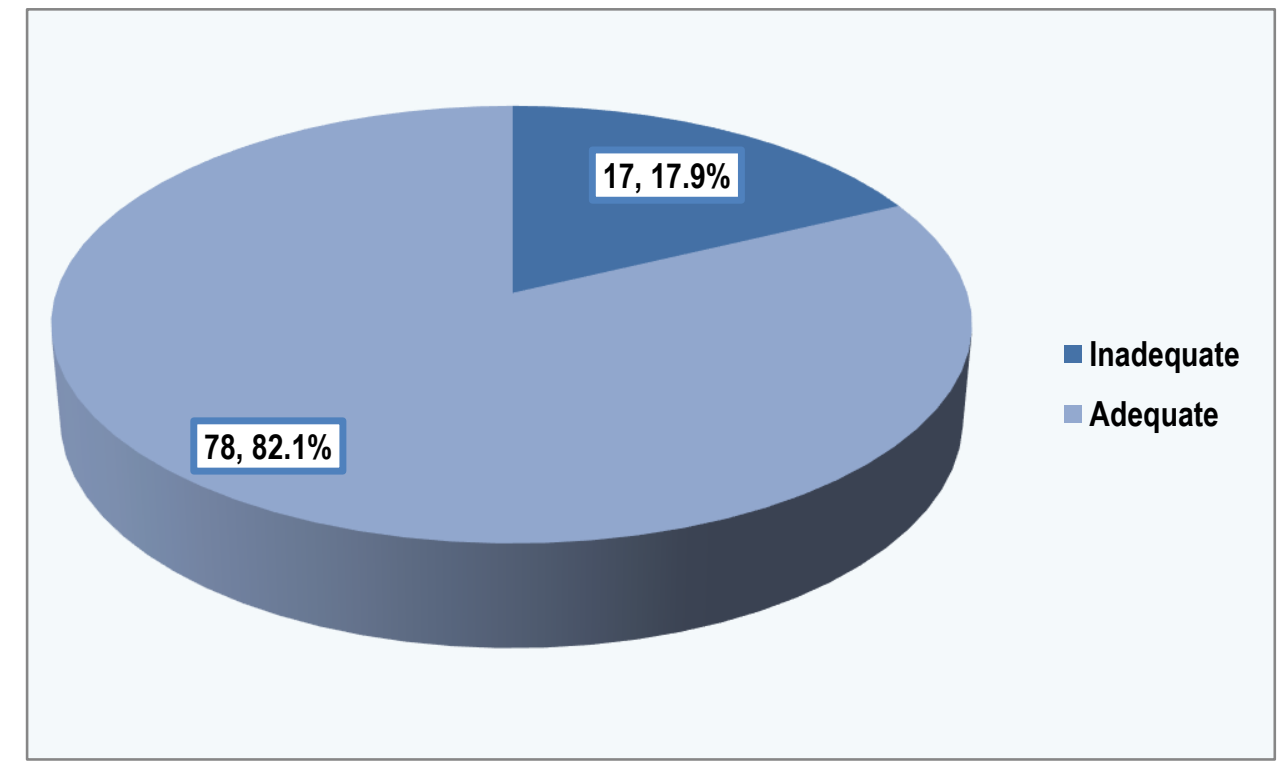

Figure 2: Level of knowledge regarding breast cancer and breast self-examination Among females in Umm Al-Qura University, Mekkah, Saudi Arabia.

Overall, adequate knowledge regarding breast cancer and breast self-examination was observed among $82.1 \%$ of the respondents as displayed in figure 2 .
From table 4, it is evident that breast cancer/BSE knowledge were not significantly associated with respondent's age and family history of breast cancer. 
Rawaa K. Damanhouri. Awareness and Attitudes Regarding Breast Cancer

Table 4: Association between breast cancer/BSE knowledge and respondent's age and family history of breast cancer.

\begin{tabular}{|c|c|c|c|}
\hline & \multicolumn{2}{|c|}{ Breast cancer/BSE knowledge level } & \multirow[t]{4}{*}{ P-value } \\
\hline & Inadequate & Adequate & \\
\hline & $\mathrm{N}=17$ & $\mathrm{~N}=78$ & \\
\hline & $\mathbf{N}(\%)$ & $N(\%)$ & \\
\hline \multicolumn{4}{|l|}{ Age (years) } \\
\hline$<25(n=67)$ & $13(19.4)$ & $54(80.6)$ & \\
\hline $25-35(n=14)$ & $1(7.1)$ & $13(92.9)$ & \\
\hline$>35(n=14)$ & $3(21.4)$ & $11(78.6)$ & $0.516^{*}$ \\
\hline \multicolumn{4}{|c|}{ Family history of breast cancer } \\
\hline Yes $(n=14)$ & $1(7.1)$ & $13(92.9)$ & \\
\hline No $(n=81)$ & $16(19.8)$ & $65(80.2)$ & $0.233^{\star *}$ \\
\hline
\end{tabular}

\section{DISCUSSION}

In order to have a successfully implemented breast cancer control program, assessment of public awareness as well as attitudes and practice of BSE should be essential components of such programs. $^{7}$

In developing countries, like Saudi Arabia, the primary goal of breast cancer awareness programs is to encourage and promote the importance of early detection. ${ }^{8}$ Therefore, this study was carried out to assess the level of knowledge about breast cancer, attitude and practicing breast self-examination (BSE) among females in Umm Al-Qura University, Makkah, Saudi Arabia.

In the current study, majority of respondent aged below 25 years and this is an advantage of this study as these young populations should gain more information on breast cancer and breast selfexamination before they reach the age of common prevalence of the disease.

Fortunately, in the present study, almost all of the respondents have heard about breast cancer and majority of them were aware of breast self-examination. In a similar study carried out in Nigeria, ${ }^{6}$ most of the respondents surveyed had heard of breast cancer $(97.3 \%)$ and $85.8 \%$ claimed they knew how (BSE) is done. The present study revealed that adequate knowledge regarding breast cancer and breast self-examination was observed among $82.1 \%$ of the respondents. This high rate could be attributed to the fact that our population was recruited from workers in a University with expected higher educational level. In a similar study carried out in Nigeria, ${ }^{9}$ it has been reported that higher education women were more knowledgeable about breast self-examination while those who had primary education were the least knowledgeable.

The most frequently reported source of information about breast cancer and BSE in the current study was social media. In a Nigerian study, ${ }^{6}$ the commonest reported source was television/radio whereas in Jordan, ${ }^{10}$ most information were obtained from friends and health workers.

Overall, adequate knowledge regarding breast cancer and breast self-examination was adequate. This is contrary to what has been reported in Jordan where knowledge about breast cancer and BSE were below average, despite they included highly educated university students, and therefore they described their results as disappointing. ${ }^{10}$

Despite adequate BSE knowledge observed in study, only onethird of women performed BSE. This is in line with the findings of Abdel Hadi, ${ }^{11}$ who found that $37.3 \%$ of his study population practiced BSE. Other studies that showed lower rates of BSE practice suggested that the practice is globally low among women, regardless of their age and occupation. ${ }^{11,12}$ However, the rates reported in this current study were higher than those described by previous Egyptian and Iranian studies, in which only 6\% and 2.7\% of the general study populations practiced BSE monthly, respectively. ${ }^{12,13}$ It has been reported that in the Middle East, breast cancer comes with a heavy cultural stigma, as exemplified by the study in which Laura Bush stated that, "Women in [the] Middle East are sometimes abandoned by their family when the disease is diagnosed, [and] such stories are discouraging". ${ }^{14}$

In the current study, never performance of breast self-examination was mainly due to decrease the confident of ability in perform it in right way (34.4\%), haven`t any symptoms of breast cancer (25\%) and ignorance of its performance (17.2\%). In a similar Jordanian study, ${ }^{10}$ women reported the reasons of not performing BSE as they did not feel that screening was necessary, and $28.8 \%$ of them reported being too busy. Therefore, it is essential to raise women's awareness and confidence regarding the life-saving benefits of BSE practice.

One of the important limitations of the study is that inclusion of participants from one institution which could impact generalizability of results.

In conclusion, despite the knowledge of women regarding breast cancer and BSE was adequate in general; the practice of screening BSE was suboptimal. Therefore, there is a need to teach women about the importance of practices for early detection techniques, such as BSE, which will enable breast cancer to be detected at an earlier stage.

\section{REFERENCES}

1. Key TJ, Verkasalo PK, Banks E .Epidemiology of breast cancer. The lancet Oncology. 2001 Mar; 2(3): p133-140, March 2001.

2. Siegel RL, Miller KD, Jemal A. Cancer statistics, 2016. CA Cancer J Clin. 2016 Jan-Feb;66(1):7-30.

3. Saggu S, Rehman H, Abbas ZK, Ansari AA. Recent incidence and descriptive epidemiological survey of breast cancer in Saudi Arabia. Saudi Med J. 2015 Oct;36(10):1176-80.

4. Ministry of Health portal of kingdom of Saudi Arabia. National Campaign for Breast Cancer Awareness. Available from: http://www.moh.gov.sa/en/healthawareness/campaigns/breastcan cer/pages/default.aspx. [Last cited October 15, 2012] 
5. World Health Organization. Breast cancer: prevention and control. Available from: http://www.who.int/cancer/detection/ breastcancer/ en/index3.html. [Last cited on Sep 17, 2016]

6. NK I, OA O, RA A, RB B, AT O. Knowledge, attitude and practice of breast self-examination among female medical students in the University Of Lagos. The Internet Journal of Health. 2009;12 (1): 1-6.

7. Ibrahim NA, Odusanya OO. Knowledge of risk factors, beliefs and practices of female healthcare professionals towards breast cancer in a tertiary institution in Lagos, Nigeria. BMC Cancer 2009;9:76.

8. Omotara B, Yahya S, Amodu M, Bimba J. Awareness, attitude and practice of rural women regarding breast cancer in Northeast Nigeria. J Community Med Health Educ 2012;2:2-4.

9. Balogun MO, Owoaje ET. Knowledge and Practice of Breast Self-Examination amongFemale Traders in Ibadan, Nigeria.Annals of Ibadan Postgraduate Medicine. 2005; 3:52-6.

10. Suleiman AK. Awareness and attitudes regarding breast cancer and breast self-examination among female Jordanian students. J Basic Clin Pharma 2014;5:74-8.

11. Abdel Hadi MS. Breast cancer awareness among health professionals. Ann Saudi Med 2000;20:135-6.

12. Ahmed F, Mahmud S, Hatcher J, Khan SM. Breast cancer risk factor knowledge among nurses in teaching hospitals of Karachi, Pakistan: A cross-sectional study. BMC Nurs 2006;5:6.
13. Haji - Mahmoodi M, Montazeri A, Jarvandi S, Ebrahimi M, Haghighat $S$, Harirchi I. Breast self-examination: Knowledge, attitudes, and practices among female health care workers in Tehran, Iran. Breast J 2002;8:222-5.

14. Bush L. Raising breast cancer awareness in the Middle East. NCICancer Bull 2007:4:9.

Source of Support: Nil.

Conflict of Interest: None Declared.

Copyright: (c) the author(s) and publisher. IJMRP is an official publication of Ibn Sina Academy of Medieval Medicine \& Sciences, registered in 2001 under Indian Trusts Act, 1882.

This is an open access article distributed under the terms of the Creative Commons Attribution Non-commercial License, which permits unrestricted non-commercial use, distribution, and reproduction in any medium, provided the original work is properly cited.

Cite this article as: Rawaa K. Damanhouri. Awareness and Attitudes Regarding Breast Cancer and Breast Self-Examination among Females in Umm Al-Qura University, Mekkah, Saudi Arabia. Int J Med Res Prof. 2016; 2 (6): 186-90.

DOI: 10.21276/ijmrp.2016.2.6.039 